\title{
Effect of the Drug Abuse on the Academic Performance of the Students/Adolescents
}

\author{
Gunjan Manish ${ }^{1 *}$, Tomar Deepali ${ }^{2}$ and Singh Neetu ${ }^{3}$ \\ ${ }^{1}$ Institute of Pharmacy, Shri JJT University, Chudela, India \\ ${ }^{2}$ Department of Pharmacy, Faculty of Lala Birkha Ram College Of Pharmacy, India \\ ${ }^{3}$ Institute of Zoology, Shri JJT University, Chudela, India \\ *Corresponding author: Manish Gunjan, Institute of Pharmacy, Shri JJT University, Jhunjhunu, India
}

\section{ARTICLE INFO}

Received: 㗀 June 06, 2020

Published: ${ }^{\mathrm{w}}$ June 23, 2020

Citation: Gunjan Manish, Tomar Deepali, Singh Neetu. Effect of the Drug Abuse on the Academic Performance of the Students/Adolescents. Biomed J Sci \& Tech Res 28(3)-2020. BJSTR. MS.ID.004652.

Keywords: Drug; Drug abuse; Addiction; Cognitive impairment; Illicit Drugs

\section{ABSTRACT}

There is no universal definition for 'drug abuse'. Drug abuse is the deliberate use of chemical substances for reasons other than intended medical purposes and which results in physical, mental, emotional or social impairment of the user. Research has found that the problem arises from many aspects: such as motherfather relationships, the way parents raise their children, the financial situation of the family, and the community, such as illicit gathering places, wrong or bad values, and neglect. Another factor affecting drug abuse is the lack of knowledge of the drug's effects. The illicit drugs are depressogens, the repeated use of which produces both the subjective feelings of depression and the neurovegetative signs such as sleep and appetite disturbance, cognitive impairment, and decreased energy characteristic of the depressed syndrome. The immediate effects have an initial stimulation which fades into relaxation accompanied by euphoria, increase ability to communicate, drowsiness, blood-shot eyes, occasional nausea and vomiting, clumsiness, decrease muscular coordination, dizziness etc. We went through questionnaire surveys which contain 60 questions distributed to 44 samples from Masterskill Global College, Ipoh, Malaysia as well as from outside adolescent from different colleges. After getting the answers of questionnaire, we did statistical analysis and found that the most obvious reasons includes for drug abuse are family problem, financial problem, community, lack of knowledge in drug's effects and also found that these factors play a vital role on academic performance. We can conclude that if required action/education of the same would be taken/given on time the students may perform well academically without taking any drug.

\section{Introduction}

The history of the human race has also been the history of drug abuse. In itself, the use of drugs does not constitute an evil. Drugs, properly administered, have been a medical blessing. For example, herbs, roots, bark leaves and plants have been used to relieve pain and help control diseases. However, over the past few decades, the use of illegal drugs has spread at an unprecedented rate and has reached at every part of the world. Many researchers have sought the cause of drug abuse/addiction, so that effective treatments and preventive methods can be implemented. Research has found that the problem arises from many aspects: family sources, such as mother-father relationships, the way parents raise their children, the financial situation of the family, and the community, such as illicit gathering places, wrong or bad values, and neglect [1]. The people adolescents spend time with also affect his/her habits. Adolescents who have friends using drugs are more prone to become addicts themselves. Friends tend to introduce others to drug use [1]. Another factor affecting drug abuse is the lack of knowledge of the drug's effects. Because of the complexity of the problem, collaboration between several groups must be implemented to increase adolescents' understanding amphetamines and themselves, to enable them to develop self-worth and to prepare them to face drug 
temptations, learning to say "No" to drugs. Society should support these adolescents in preparing them for such situations. Friends, family, teachers and other members of the community should give support to adolescents so that they are emotionally and mentally ready to fight against drugs.

Godley mentions that, paying little heed to the idea of the connection between academic achievement and substance use, schools are a significant potential intercession condition for teenagers who are in danger for substance use problems [2]. Indeed, our own discoveries and those of Engberg and Morral recommend that pre-adult medication use is identified with decreases in continued commitment in scholarly interests, which infers that mediations laid out by Godley could improve school commitment and attendance [2]. Engberg and Morral's information are especially convincing, as they exhibit that lessening substance use through a treatment program builds school participation among overwhelming medication utilizing youths. Taken together, the consequences of both observational examinations recommend that diminishing medication use will deliver enhancements in scholarly results.

Consequences of the two examinations $[3,4]$ underscore the significance of explaining the systems by which substance use impacts academic results. Research proposes two potential mechanisms. First, substance use itself may influence intellectual improvement which, further, decreases academic accomplishment and reduces academic progression. Late investigations have appeared overwhelming substance use can prompt issues with working memory and attention because of changes in adolescent brain activity [4]. These memory and attention issues may in turn, prompt abatements in academic performance and engagement in school, and ultimately results in high risk of school problems and dropouts. Moreover, these discoveries have been accounted for heavy drinking and drug-using adolescents (like the clinical example utilized by Engberg and Morral) [5], and it is indistinct whether such impacts would emerge at lower level of utilization. In addition, the magnitude and in terms of whether they extend to perpetual quality of these impacts are hazy as far as whether they stretch out to impair academic functioning. For instance, studies $[6,7]$ recommend that withdrawal is a significant indicator of the neurocognitive deficits related with adolescent drinking, however it isn't evident whether prolonged periods of restraint redresses these shortfalls or whether they are permanent.

Alternatively, it could be that drug and alcohol use during adolescence leads to association with antisocial peer groups, which in turn diminishes school engagement and increases other behavioral and social problems. Surely, as Godley and the present examinations support, substance use is related to many school-related outcomes that have a strong behavioral and social component. That is, results, such as, school grades; attendance, school completion and dropout are impacted not only by intellectual working, but also by inspiration, hierarchical aptitudes and social/ behavioral abilities. In other words, the impacts of substance use on academic outcomes may have motivational, social and behavioral components in addition to any consequences for perception and subjective advancement. Thus, negative academic outcomes may be due to both the direct effect of substance use on In this way, negative academic results might be because of both the immediate impact of substance use on cognitive skills as well as the constellation of motivational, social and behavioral risk factors associated with substance use in adolescence.

\section{Effects of Alcohol Consumption on Academic Perfor- mance}

There is little doubt that alcohol can have a negative effect on academic success. One national study indicates that college students with an "A" average consume an average of only 3.3 drinks per week, while "D" students consume an average of 9 drinks per week. Some Sobering Facts: Alcohol has been linked to $40 \%$ of incidents of lowered academic performance and 25\% of college dropouts. The heaviest drinkers make the lowest grades. Increases in average number of drinks per week are related to decreased class attendance and getting behind on school work.

\section{Short-Term Effects of Intoxication}

Drinking to intoxication reduces REM sleep, which impairs memory and concentration for up to 72 hours:

a) Sleep: Intoxication inhibits REM sleep, a stage of sleep associated with learning and memory functions. REM deprivation has been linked with learning impairment.

b) Memory: Alcohol impairs memory by inhibiting the transfer and consolidation of information into long-term memory.

c) Concentration: Perhaps most importantly, your attention span is shorter for periods up to three days following intoxication, resulting in poor note taking, decreased reading speed and reading comprehension, less efficient studying, and poor abstract thinking.

Every country in the world, developed or developing, incurs substantial costs as a result of damages caused by substance abuse [8]. The World Health Organization (WHO) estimates that 1.1 billion people, representing a third of the world population above the age of 15 years, use tobacco, principally in the form of the cigarettes. Of these smokers, 800 million, 700 million of them males, live in developing countries [9]. While smoking rates have been declining in the developed world, they have increased in the developing countries by as much as 50 percent, especially in Asia and in the Pacific region, over the last decade. Addiction to tobacco is therefore a major problem in the developing countries. According to the same report, tobacco causes four million deaths annually, not including prenatal morbidity and mortality. This figure is projected 
to rise to 1.6 million by the year 2025,70 percent of which will occur in the developing world if current trends continue [10].

\section{So why do College Students Continue to Drink and Use} Drugs?

a. Some feel pressured to use drugs or alcohol at social gatherings

b. Drug or alcohol abuse offers a way to escape from school or work related stress, financial worries or relationship problems

c. Provide a way to compensate for feelings of shyness or low self-esteem

d. These drugs act as a substitute for satisfying relationships, educational accomplishments or self- fulfillment.

\section{Aim and Objectives of the study}

The main objective of this study is to investigate the effect of alcohol consumption on student's academic performance. The specific objectives were:

a. To find out whether alcohol consumption has any negative effect on students' psychological conditions or academic performance.

b. To find out whether alcohol consumption has any health effect on students

c. To find out the characteristics associated with those who were involved in alcoholism

d. To explore the academic accomplishment measures that was commonly associated with alcohol consumption.

\section{Significance of the Study}

The conclusions made from this study will be useful to students, families, scholars, cooperate bodies and the government in the following ways;

a. Reveal the consequence of alcohol consumption on academic performance of students.

b. Sets a base to promote further research concerning alcohol consumption on other additional variables than academic performance.

c. Enlighten the health implications associated with alcohol consumption to the students.

d. Support the parents to educate their children about the adverse effect of alcohol consumption.

e. Empower government bodies to pass laws against alcohol consumption while in school.

\section{Recommendation}

Based on the outcomes of the study, the recommendations that have been made are as following;

a) Government bodies must endorse laws for prohibiting sales of alcohol to youths and students.

b) Run constant awareness program on the threats of alcohol consumption on the academic performance for students starting from fresher's to those in their final year.

c) Prohibits the alcohol promotional sale by companies in the higher institutions

d) Strictly prohibit operating of bars within or around higher institutions.

e) Carry out Self-esteem training periodically, for letting the students understand that alcohol is not a self-esteem booster.

f) Need to conduct periodic alcohol level screening in the students and a stiff penalty for those that could not meet the standards of screening test.

\section{Research Methodology}

We had collected some literatures and gone through it, gathered the important data that relevant to our topics. Few of the literature have provided some questionnaire which was helpful while preparing our survey questions. From that we constructed a questionnaire consisting of 60 questions. We distributed the questionnaire to 94 respondents consisting of 44 male and 50 female.

\section{Research Design}

This examination which analyzed the impact of alcohol consumption on academic performance of student's especially in Masterskill Global College, Ipoh, Malaysia as well as in outside adolescent from different colleges adopted a survey research design. The adopted research design for the study was descriptive type of survey.

\section{Area of the Study}

The study took place in Masterskill Global College, Ipoh, Malaysia. This is a non-conservative college where students have their independence/opportunities. Some students live in the hostel while others reside outside the campus. The population of the study comprised of 94 respondents from Masterskill Global College, Ipoh, Malaysia as well as outside adolescent from different nearby colleges.

\section{Sample and Sampling Procedure}

Simple random sampling was used in selecting the respondents. Firstly, we prepare an exhaustive list (sampling frame) of all 
members of the population of interest. From this list, the sample is drawn using random number generator so that each and every person has an equal chance of being drawn during each selection round.

\section{Research Instrument}

The instrument used for data collection in this study was designed by the researcher. The instrument consisted of three sections of questionnaire. Section A was designed to get basic information on the respondents associated with socio-demographic characteristics with alcohol consumption, section B contained structured questions designed to obtain information on why, how and when they do take alcohol while section $C$ contain questions designed to obtain information about the respondents also involved in other bad habits like smoking and drug abuse. All the questions involved in the above sections have direct or indirect association with academic performance.

\section{Data Collection}

In this study the data collection is done by the most customary technique of offline data collection, using paper forms containing the designed questions on paper sheets of paper and distributing them. The researcher randomly selected 94 students. The respondents were approached, having acquainted them of the researcher's intention. The respondent's consent was duly sought by asking them whether they will participate in the study. Those who responded in the confirmatory contributed in the study were requested to fill the paper forms. Additionally, the participants confidentiality was guaranteed and therefore, they should asked not to write their names on the questionnaires. Later the obtained data is compiled into tables for further analysis.

\section{Method of Data Analysis}

Data generated in this study were statistical analysis with the help of pie chart, tables and cross tabulation. The percentage, Chisquare test values and p-value were also calculated using Epi Info Software to check the survey data for outliers and inconsistent data.

\section{Results}

This section present the data of the findings compiled from the respondents in tabular form (Tabels 1-5) (Figures 1-5)
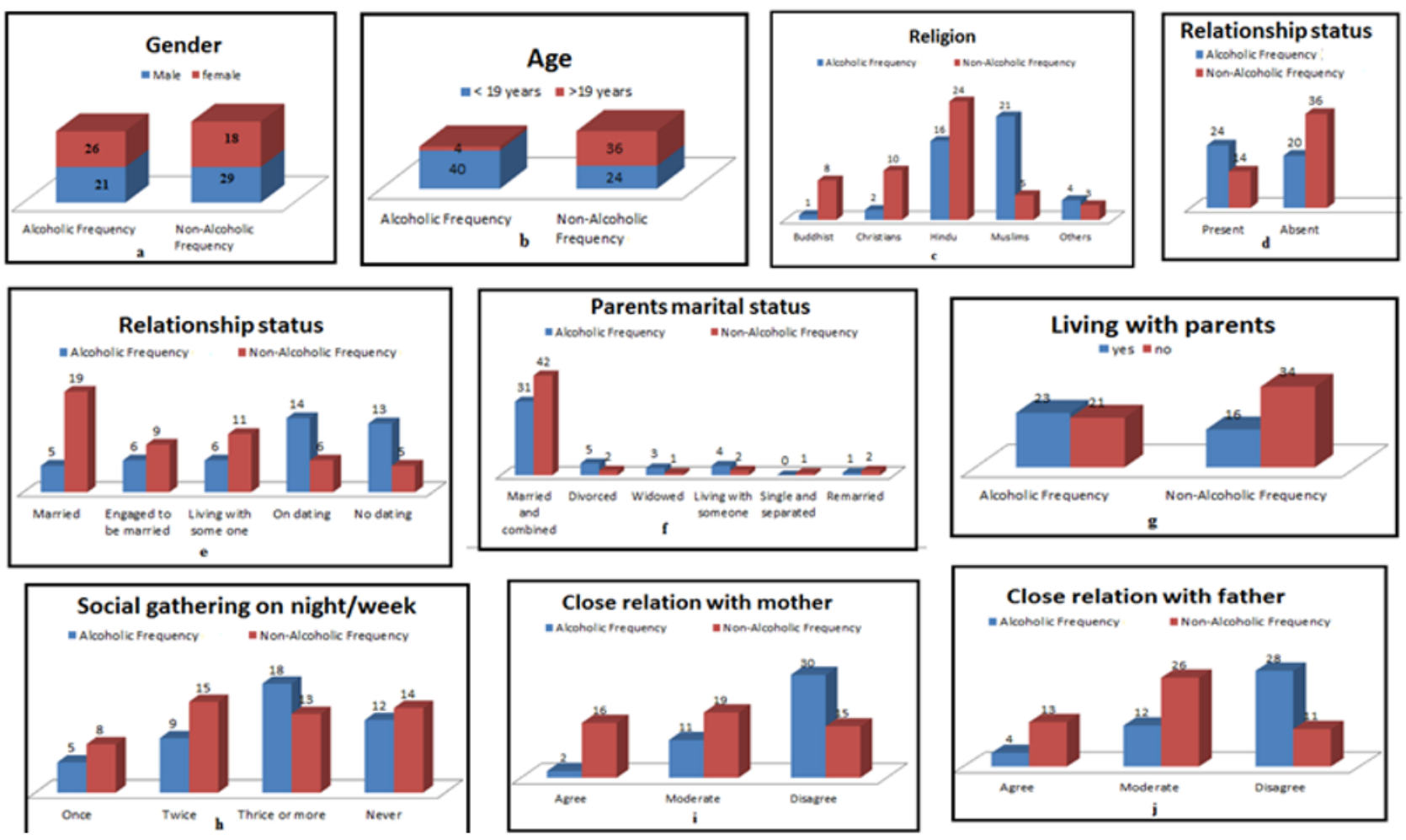

Figure 1. 

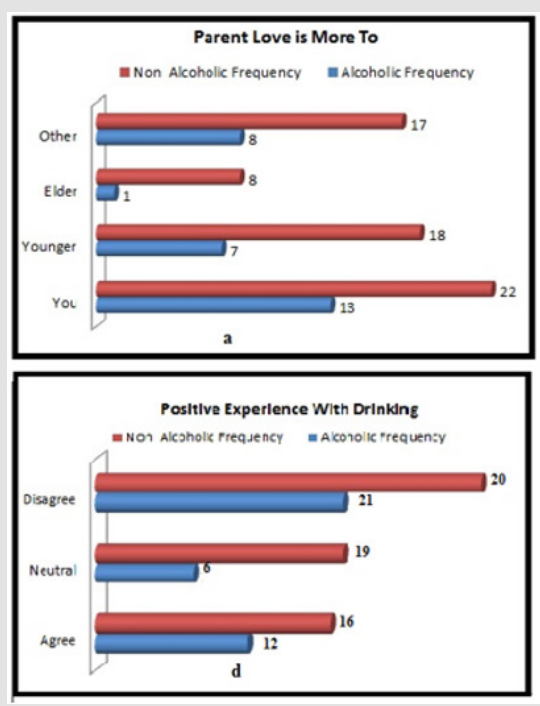
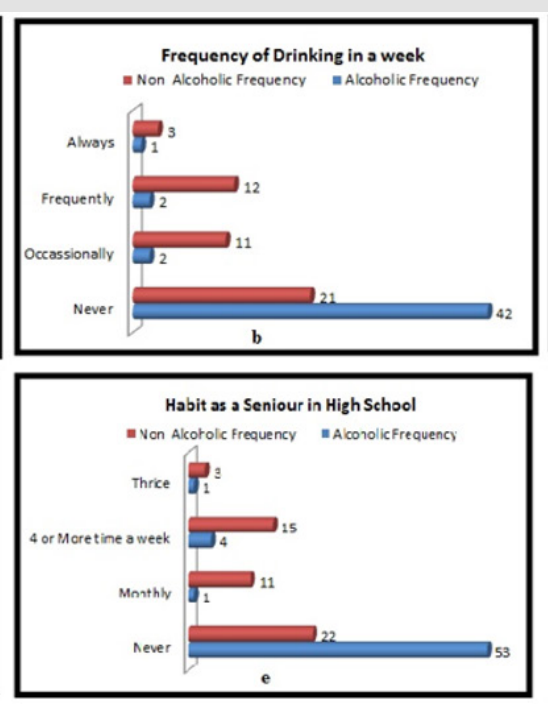

Figure 2.
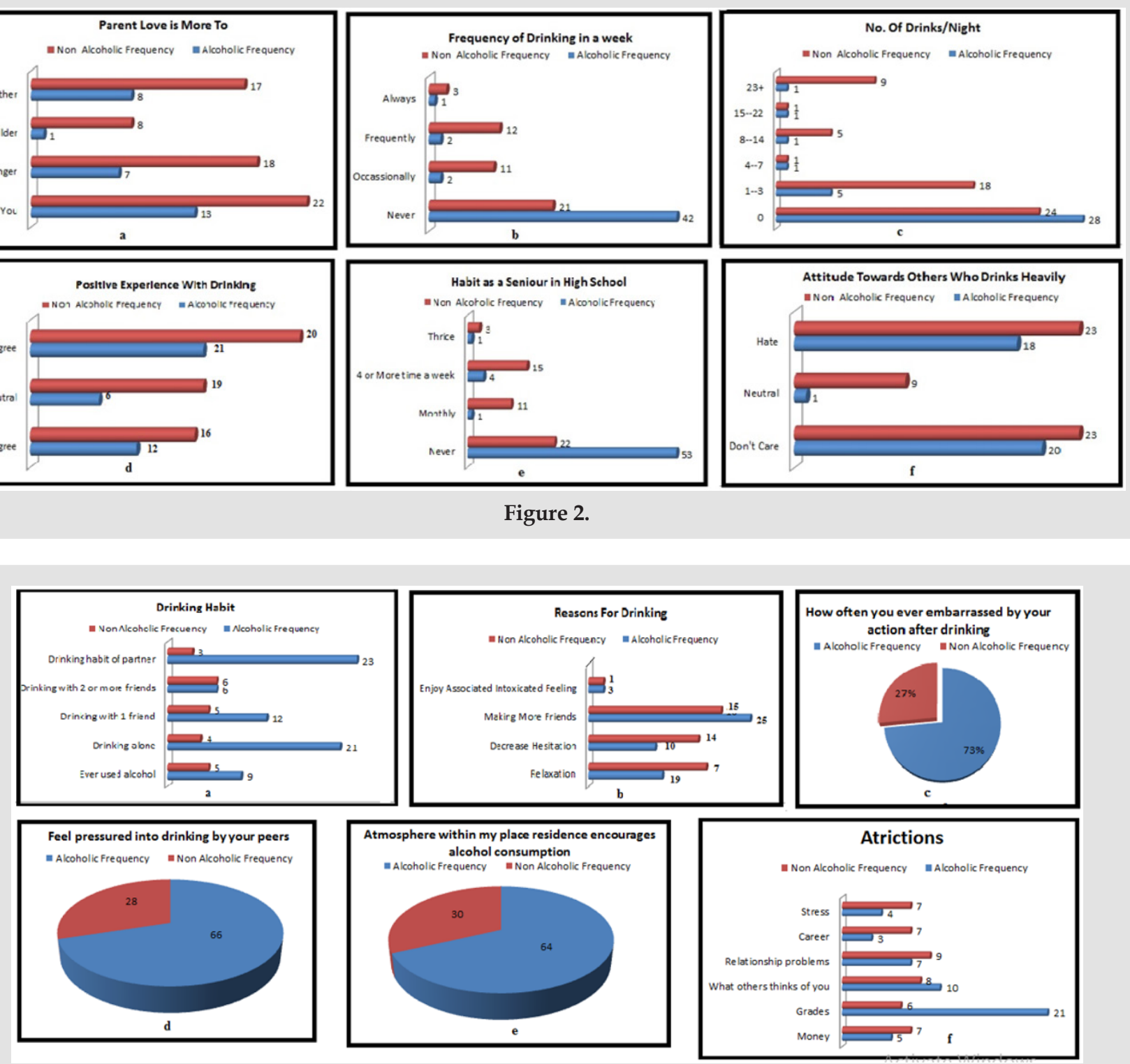

Figure 3.
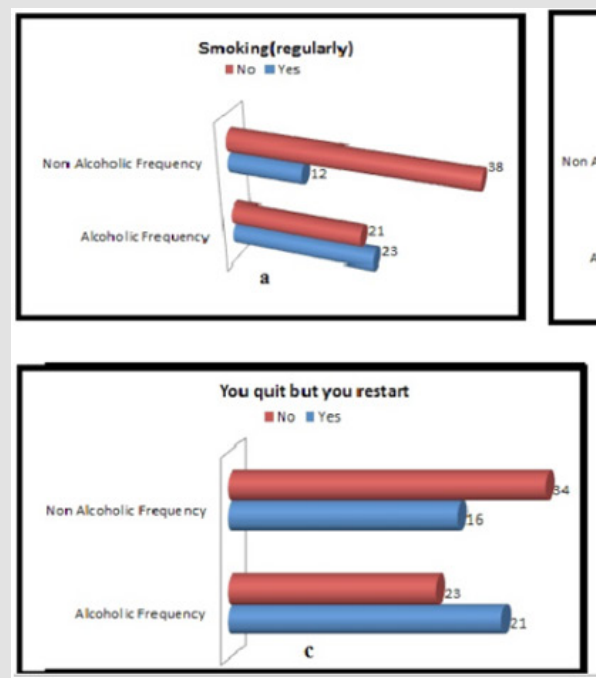
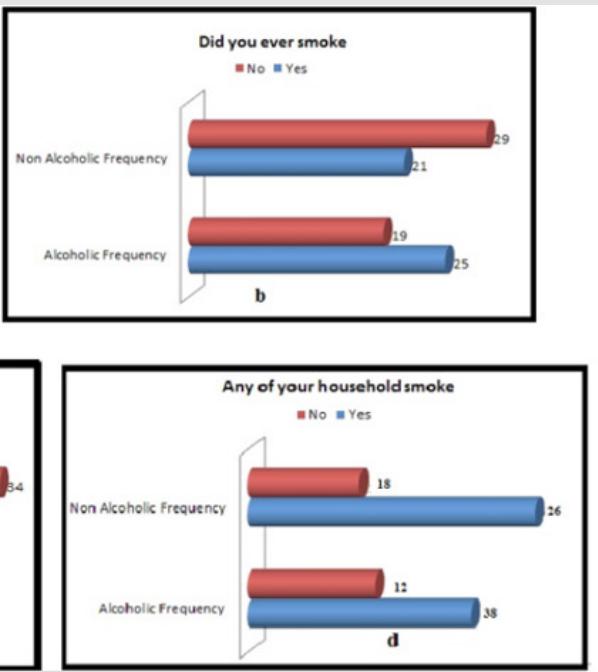

Figure 4 .

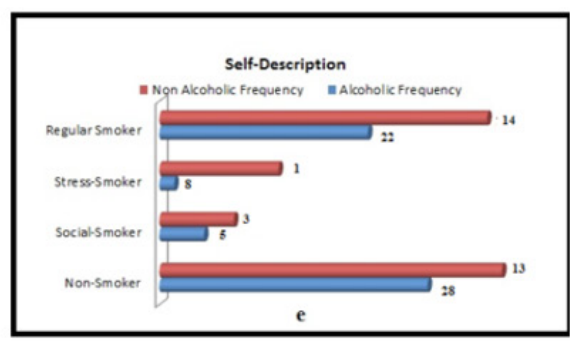




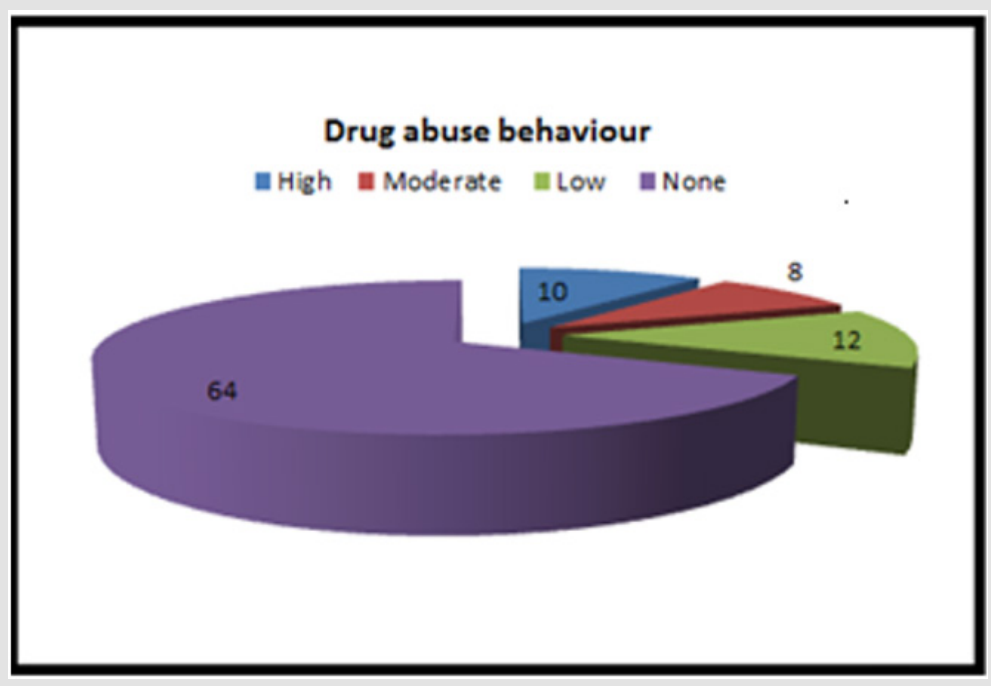

Figure 5.

Table 1: Association of Socio-demographic characteristics with alcohol consumption (n=94). (Figure 1)

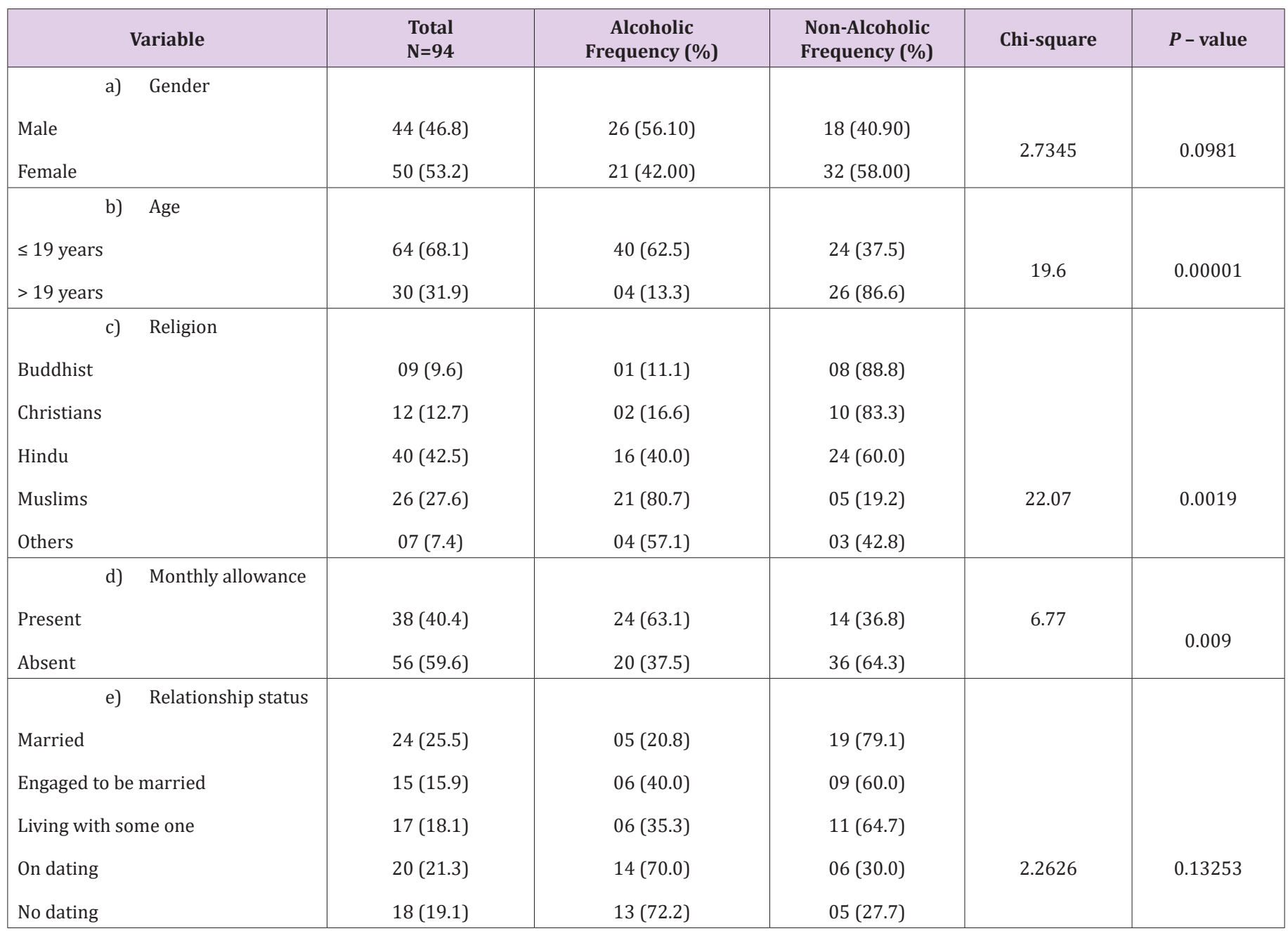




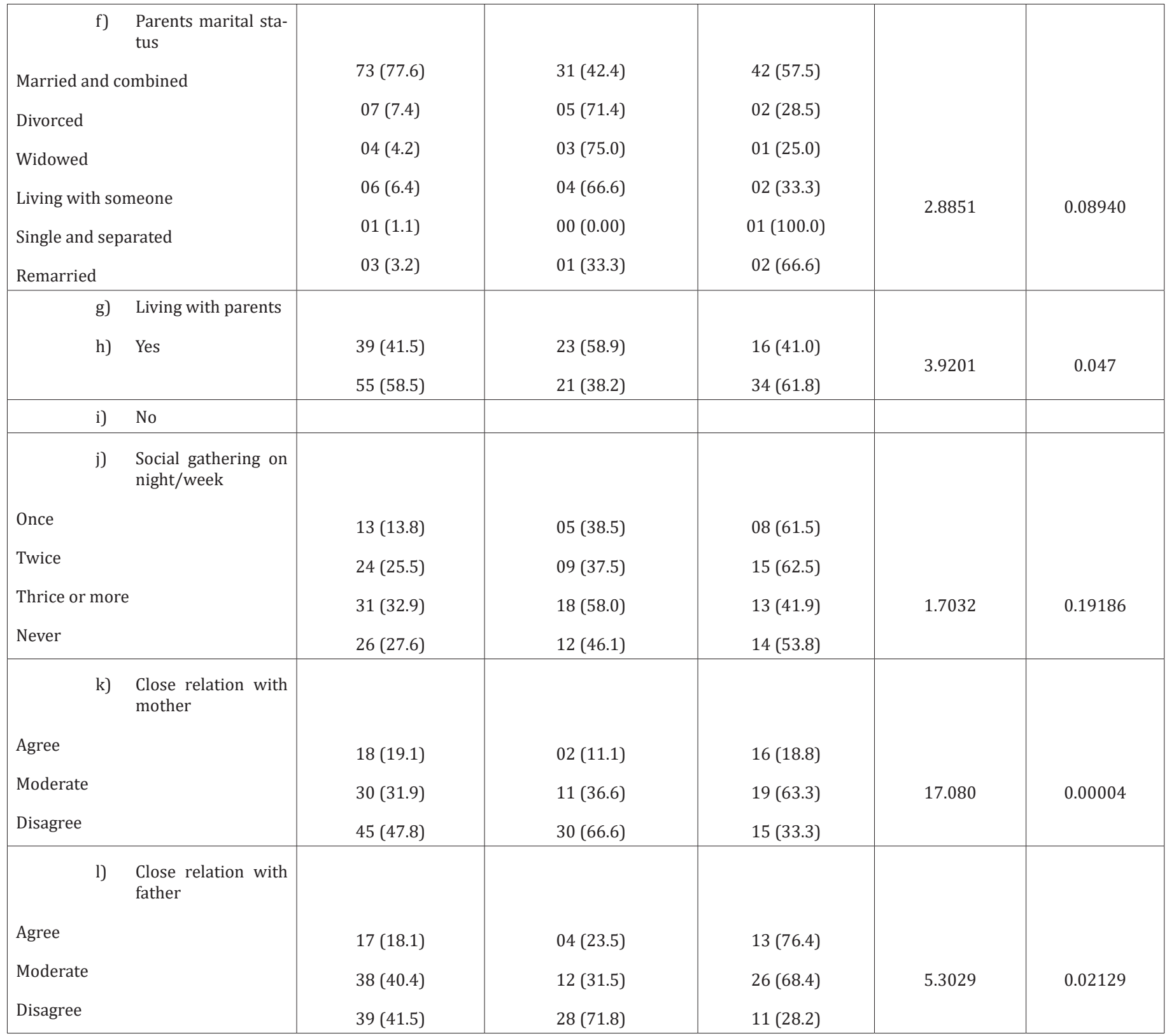

Table 2: Association of personal experences with alcohol consumption ( $n=94)$ (Figure 2).

\begin{tabular}{|c|c|c|c|c|c|}
\hline Variable & $\begin{array}{l}\text { Total } \\
\mathrm{N}=94\end{array}$ & $\begin{array}{c}\text { Alcoholic } \\
\text { Frequency (\%) }\end{array}$ & $\begin{array}{l}\text { Non-Alcoholic } \\
\text { Frequency (\%) }\end{array}$ & Chi-square & $P$ - value \\
\hline \multicolumn{6}{|c|}{ a) Parent love is more to } \\
\hline You & $35(37.23)$ & $16(45.71)$ & $19(54.29)$ & & \\
\hline Younger & $25(26.59)$ & $07(28.00)$ & $18(72.00)$ & & \\
\hline Elder & $09(9.57)$ & 01(11.10) & 08(88.90) & 5.7568 & 0.1240 \\
\hline Other & $25(26.59)$ & $06(24.00)$ & $19(76.00)$ & & \\
\hline \multicolumn{6}{|c|}{ b) Frequency of Drinking in a Week } \\
\hline Never & $63(67.02)$ & $42(66.66)$ & $21(31.74)$ & & \\
\hline Occasionally & $14(14.89)$ & $02(14.28)$ & $11(78.57)$ & & \\
\hline Frequently & $14(14.89)$ & $02(14.29)$ & $12(85.71)$ & 21.3736 & 0.0001 \\
\hline Always & $03(3.19)$ & $01(33.3$ & $02(66.67)$ & & \\
\hline
\end{tabular}




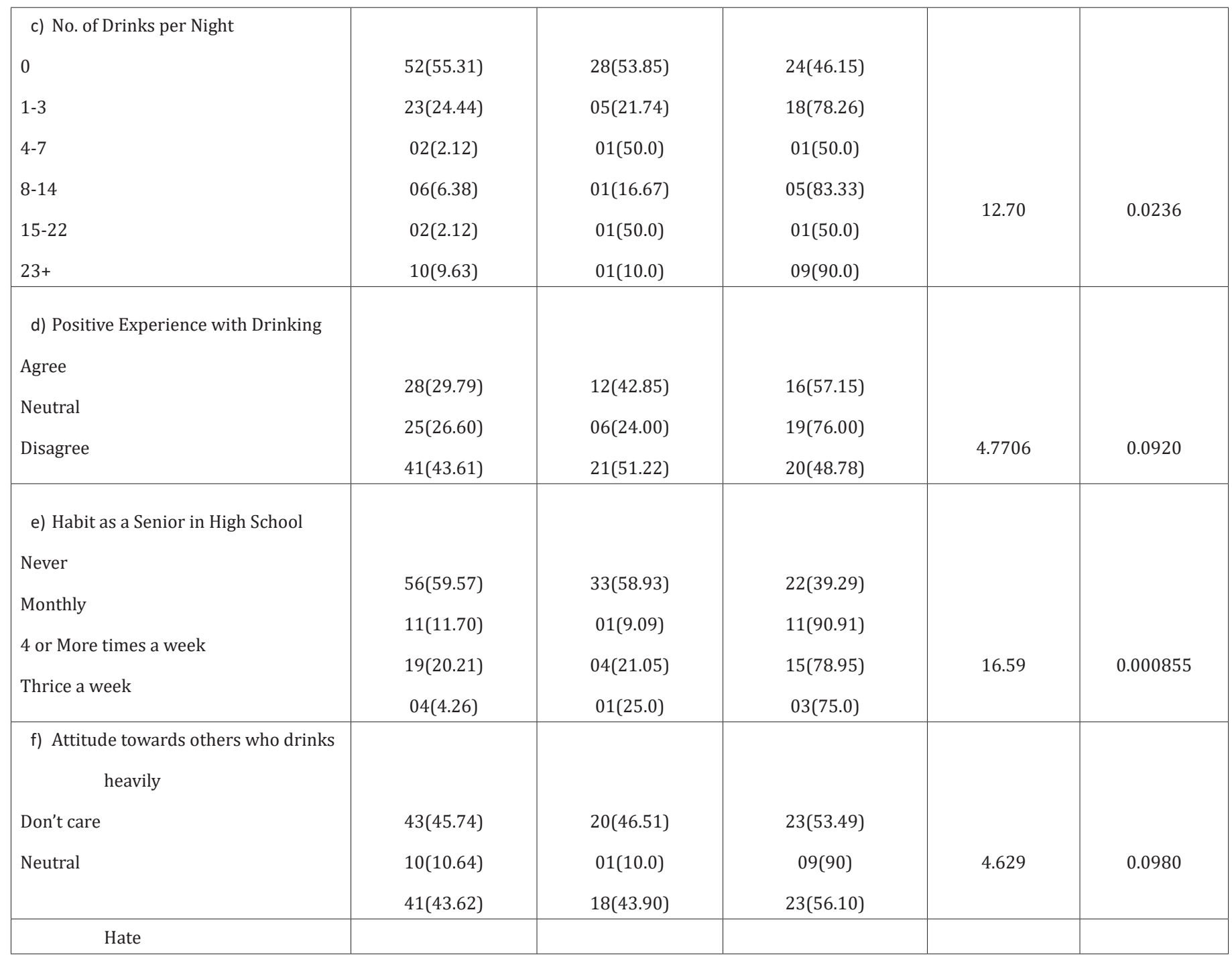

Table 3: Association of Behavoural characteristics with alcohol consumption ( $n=94)$ (Figure 3).

\begin{tabular}{|c|c|c|c|c|c|}
\hline Variable & $\begin{array}{l}\text { Total } \\
\mathrm{N}=94\end{array}$ & $\begin{array}{c}\text { Alcoholic } \\
\text { Frequency (\%) }\end{array}$ & $\begin{array}{l}\text { Non-Alcoholic } \\
\text { Frequency }(\%)\end{array}$ & Chi-square & $P$-value \\
\hline a) Drinking Habit & & & & & \\
\hline Ever used alcohol & $14(14.90)$ & $9(64.29)$ & $05(35.71)$ & & \\
\hline Drinking alone & $25(26.60)$ & $21(84.0)$ & $04(16.0)$ & & \\
\hline Drinking with 1 friend & $17(18.08)$ & $12(70.59)$ & $05(29.41)$ & & \\
\hline Drinking with 2 or more friends & $12(12.77)$ & $6(50.0)$ & $06(50.0)$ & 8.73 & 0.0680 \\
\hline Drinking habit of partner & $26(27.65)$ & $23(88.46)$ & 03(11.54) & & \\
\hline b) Reasons for Drinking & & & & & \\
\hline Relaxation & $26(27.65)$ & $19(73.07)$ & $07(26.30)$ & & \\
\hline Decrease hesitation & $24(25.53)$ & $10(41.70)$ & $14(58.30)$ & & \\
\hline Making more friends & $40(42.55)$ & $25(62.50)$ & $15(37.50)$ & 5.7082 & 0.1267 \\
\hline $\begin{array}{l}\text { Enjoy associated intoxication fee- } \\
\text { ling }\end{array}$ & $04(4.25)$ & $03(75.00)$ & $01(25.00)$ & & \\
\hline $\begin{array}{l}\text { c) How often you ever embar- } \\
\text { rassed by your actions after } \\
\text { drinking }\end{array}$ & $94(100)$ & $69(73.40)$ & $25(26.60)$ & 20.5957 & 0.0000056 \\
\hline
\end{tabular}




\begin{tabular}{|r|c|c|c|c|}
\hline d) $\begin{array}{c}\text { Feel pressured into drin- } \\
\text { king by your peers }\end{array}$ & $94(100)$ & $66(70.21)$ & $28(29.79)$ & 15.3617 \\
\hline $\begin{array}{l}\text { Atmosphere within my pla- } \\
\text { ce of residence encourages } \\
\text { alcohol consumption }\end{array}$ & $94(100)$ & $64(68.09)$ & $30(31.91)$ & 12.2978 \\
\hline f) Astriction & $12(12.80)$ & $05(41.67)$ & 0.0000887 \\
Money & $27(28.72)$ & $21(77.78)$ & $06(22.22)$ & 0.000453 \\
Grades & $18(19.14)$ & $10(55.56)$ & $08(44.44)$ & $09(56.25)$ \\
What others thinks of you & $16(17.02)$ & $07(43.75)$ & $07(70.0)$ & 11.2198 \\
Relationship problems & $10(10.63)$ & $03(30.0)$ & $07(63.64)$ & 0.047191 \\
Career & $11(11.69)$ & $04(36.36)$ & & \\
Stress of life problems & & & \\
\hline
\end{tabular}

Table 4: Effect of Smoking on the Academic Performance (Figure 4).

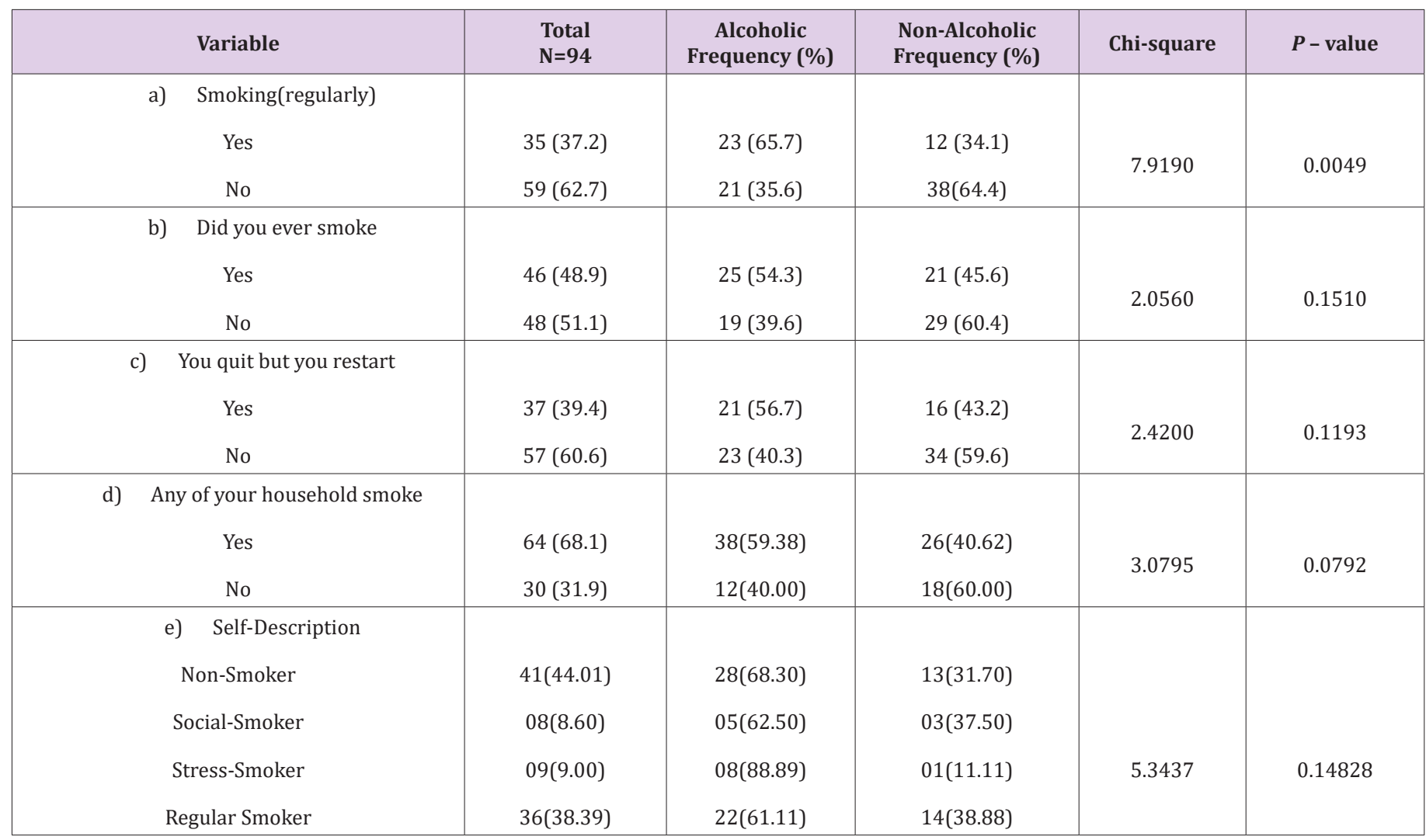

Table 5: Drug abuse behaviour among study participants ( $n=94)$, (Figure 5).

\begin{tabular}{|c|c|}
\hline Drug abuse behaviour & Frequency (\%) \\
\hline High & $10(10.64)$ \\
\hline Moderate & $08(8.51)$ \\
\hline Low & $12(12.7)$ \\
\hline None & $64(68.08)$ \\
\hline
\end{tabular}

\section{Discussıon}

The objective of this study was to explore the connotation between alcohol consumption on academic performance amongst college students. The study revealed that male students are more susceptible to drug abuse than their female counterpart. The findings are consistent with findings from other studies conducted in the New Zealand [11], Nigeria [12], United States [13], and Australia [14] where males have recounted consuming alcohol at lethal levels than females. The students mainly abused alcohol, cigarettes, and drugs because they are still in their influential stage and might easily fall victim to experimentations with drug. This study also 
implies that the high risk age group for substance use consists of majority of respondents within the adolescent period. The alcohol consumption is high in Muslim's. The study revealed that the main factors for a students use of alcohol is parental lifestyle, attachment, peer influence and commitment to conventional activities (for example reading books, sports and religious activities) [15]. It was found that the main reasons adolescents use drugs were personal factors, family environment, and social environment [1]. Students use drugs mostly once a week; to feel good, to keep awake, and some to sleep [16]. The foremost reasons why students started abusing substances were mainly to supposedly 'enhance' their academic performances and some students combined prescription stimulants with alcohol for recreational purposes [17].

\section{Conclusion}

This paper has presented a remarkable relationship between the alcohol consumption and emotional wellness with academic performance. The outcomes from this study are much comparable with other studies which demonstrate that students with moderate/ high psychological distress were not being able to complete their assignments and are more likely faces academic problems. It is difficult to conduct direct comparisons of our study findings with that of other studies, because of the miscellany approaches employed in demonstrating the alcohol positive/ negative effect on psychological distress and academic performance (e.g. time, whether the no. of drinks were employed in estimating alcohol amount of consumption, different reasons for drinking etc. Though, our association between alcohol consumption and educational impairments were properly demonstrated.

\section{Acknowledgement}

I would like to thank the management of Masterskill University, Malaysia to allow us for this study and also to motivate and facilliate the required things for this study.

\section{Author Contributions}

Concept-M.G.; Design-M.G \& N.S.; Supervision-M.G.; Resources - M.G. Materials - M.G., Data Collection and/or Processing - M.G., Analysis and/or Interpretation -D.T.; Literature Search -M.G., D.T; Writing - M.G, N.S \& D.T.; Critical Reviews - M.G., D.T.

\section{Conflict of interest}

None.

\section{References}

1. Laoniramai P, Laosee OC, Somrongthong R, Wongchalee S, Sitthi amorn C (2005) Factors affecting the experiences of drug use by adolescents in A Bangkok Slum. Southeast Asian Journal of Tropical Medicine and Public Health 36(4): 1014-1019.

2. King KM, Meehan BT, Trim RS, Chassin L (2006) Substance use and academic outcomes: Synthesizing findings and future directions. Addiction 101(12): 1688-1689.

3. Engberg J, Morral AR (2006) Reducing substance use improves adolescents' school attendance. Addiction. 101(12): 1741-1751.

4. King KM, Meehan BT, Trim RS, Chassin L (2006) Marker or mediator? The effects of adolescent substance use on young adult educational attainment. Addiction 101(12):1730-1740.

5. Monti PM, Miranda Jr R, Nixon K, Sher KJ, Swartzwelder HS, et al. (2005) Adolescence: booze, brains, and behavior. Alcoholism: Clinical and Experimental Research 29(2): 207-220.

6. Tapert SF, Brown SA (1999) Neuropsychological correlates of adolescent substance abuse: four-year outcomes. Journal of the International Neuropsychological Society 5(6): 481-493.

7. Brown SA, Tapert SF, Granholm E, Delis DC (2000) Neurocognitive functioning of adolescents: Effects of protracted alcohol use. Alcoholism: clinical and experimental research 24(2): 164-171.

8. (2005) World drug report. United Nations Publications.

9. Kitchen T, Schneider RH (2007) Crime prevention and the built environment. Routledge.

10. (2003) International Narcotics Control Board (INCB) Report: United Nations Organization Report.

11. McGee R, Kypri K (2004) Alcohol-related problems experienced by university students in New Zealand. Australian and New Zealand journal of public health 28(4): 321-323.

12. Osa-Edoh GI, Egbochukwu EO (2012) Classification of frequency abused drugs amongst Nigerian youth and the social influences: Implications for counselling. AFRREV STECH: An International Journal of Science and Technology 1(3): 161-177.

13. Colby SM, Swanton DN, Colby JJ (2012) College students' evaluations of heavy drinking: The influence of gender, age, and college status. Journal of College Student Development 53(6): 797-810.

14. Hallett J, Howat PM, Maycock BR, McManus A, Kypri K, et al. (2012) Undergraduate student drinking and related harms at an Australian university: web-based survey of a large random sample. BMC Public Health 12(1): 12-37.

15. Onongha GI (2012) The influence of some factors on alcohol use and abuse among education students of Osun state university, Nigeria. International Journal of Humanities and Social Science 2(11): 276-283.

16. Okoza J, Aluede O, Fajoju S, Okhiku I (2009) Drug abuse among students of Ambrose Alli University, Ekpoma, Nigeria. European journal of social sciences 10(1): 85-92.

17. Mehta H, Rouf A (2013) A Comparative Study of Drug Abuse among Students at a Sydney University. Journal of Drug Addiction, Education, and Eradication 9(1/2): 11. 
ISSN: 2574-1241

DOI: $10.26717 /$ BJSTR.2020.28.004652

Gunjan Manish. Biomed J Sci \& Tech Res

(C) (i) This work is licensed under Creative Submission Link: https://biomedres.us/submit-manuscript.php

\begin{tabular}{ll}
\hline BIOMEDICAL & Assets of Publishing with us \\
RESERCHES & - Global archiving of articles \\
- Immediate, unrestricted online access & - Rigorous Peer Review Process \\
\hline https://biomedres.us/
\end{tabular}

